This is the final peer-reviewed accepted manuscript of:

Biolcati, R., Palareti, L. \& Mameli, C. What Adolescents Seeking Help Teach us About a School-Based Counseling Service. Child Adolesc Soc Work J 35, 45-56 (2018)

The final published version is available online at: 10.1007/s10560-017-0503-7

Rights / License:

The terms and conditions for the reuse of this version of the manuscript are specified in the publishing policy. For all terms of use and more information see the publisher's website.

This item was downloaded from IRIS Università di Bologna (https://cris.unibo.it/)

When citing, please refer to the published version. 


\title{
What Adolescents Seeking Help Teach us About a School-Based Counseling Service
}

\author{
Roberta Biolcati · Laura Palareti · Consuelo Mameli
}

\begin{abstract}
Adolescents are reluctant to seek help, especially those at psychopathological risk. School may represent the ideal setting to intercept teens in trouble by reducing some barriers to help-seeking behavior; despite this, some obstacles remain difficult to ov ercome. The present study, involving a large sample $(\mathrm{N}=2235)$ of secondary school students, aims to investigate the effectiveness of a counseling service as part of a multifaceted school-based prevention program. The counseling service is assessed by comparing students who asked for help with their peers in terms of their psychosocial characteristics, risk profiles and perceptions of the strategies that professionals adopt in order to reduce the barriers to individual counseling. Our findings reveal the capacity of individual counseling to serve the most vulnerable adolescents, with the exception of students who might be at risk of school drop-out. The effectiveness of the program implementation theory and the strength of particular strategies used to reduce barriers are discussed.
\end{abstract}

Keywords Barriers themes ' Help-seeking behavior · School-based counseling $\cdot$ Prevention $\cdot$ Adolescents

\section{Introduction}

Adolescence appears to be a vulnerable period for the development of risk behaviors and mental health problems (Sheffield, Fiorenza, \& Sofronoff, 2004; Sweeting, Young,

Department of Education Studies, University of Bologna, Via Filippo Re 6, 40126 Bologna, Italy
West, \& Der, 2006). Recent studies indicate that from 10 to $20 \%$ of adolescents experience clinically significant men-tal health disorders that would require a timely assessment as well as appropriate interventions (Jackson, Henderson, Frank, \& Haw, 2012; Vostanis, Humphrey, Fitzgerald, Deighton, \& Wolpert, 2013).

Despite the high prevalence of psychological difficulties, young people are generally loath to ask for profes-sional help (Corry and Leavey, 2017; Dubow, Lovko, \& Kausch, 1990; Garland and Zigler, 1994; Leavey, Rothi, \& Paul 2011; Slone, Meir, \& Tarrasch, 2013). About half of all the adolescents with psychological or behavioral problems actually avoid formal services (Husky, McGuir, Flynn, Chroswski, \& Olfson, 2009 ; Raviv, Raviv, Vago-Gefen, \& Fink, 2009), thus falling into the service gap, namely the gap created when those who need or seek help do not receive it (Kushner and Sher, 1991; Stefl and Pros-peri, 1985). The Italian preadolescent mental health project (PrISMA; Frigerio et al., 2009) — carried out to estimate the prevalence and features of mental health problems in urban preadolescents-confirms this tendency. Indeed, this study showed that more than $80 \%$ of participants with sig-nificant mental health problems had not yet consulted men-tal health services.

This evidence is consistent with other studies reporting a large gap between mental health services use and the need for them, both in American and in European countries (Saunders, Resnick, Hoberman, \& Blum, 1994; Sourander et al., 2001). In discussing young people's reluctance to seek professional help for emotional fragility and other kinds of difficulties, several authors have put forward the idea that the school context represents a central setting for the promotion of psychological and social well-being and for early mental health interventions (Greenberg, 2010; Vostanis et al., 2013; Wilson and Lipsey, 2007). Indeed, 
school-based services may offer several advantages compared to traditional mental health settings because they can reduce some of the barriers to help-seeking behaviors such as cost, transportation, and stigma (Catron, Harris, \& Weiss, 1998; Wu et al., 2001). Interventions delivered within the school setting thus have the potential to become one of the many normalized services embedded in the educational culture (Colognori et al., 2012).

Although the school potentially represents a facilitating environment for early intervention, there is no guarantee that a school-based counseling service may actually reach teenagers with a high risk index and discomfort (Vanheusden et al., 2008). To achieve this goal, the service offered should be able to overcome most of the barriers that hinder requests for help.

Starting from these premises, in the first section of this paper we present a theoretical framework on adolescents' help-seeking behaviors. Then, we illustrate the context and the main features of the counseling service studied, exploring the strengths and weaknesses of this particular service through a comparison between students who went to the counselor with students who did not in regard to their perceptions of barriers and psychosocial characteristics.

\section{Features of Help-Seeking Behaviors in Adolescence}

Several studies have attempted to clarify the characteristics of adolescents who seek professional help (D'Avanzo et al., 2012; Kuhl, Jarkon-Horlick, \& Morrissey, 1997). In general, adolescents prefer to seek help from informal sources, such as family and friends, than from formal ones, such as teachers, psychologists and school counselors (Schonert-Reichl et al., 2013; Rickwood and Braithwaite, 1994), and this trend is more pronounced for the youngest teenagers (Boldero and Fallon, 1995; Sears, 2004). Gender is also an important factor. Indeed, one of the most consistent pieces of evidence in this research area is that girls are more willing than boys to ask for help in terms of mental health, counseling or academic support (Raviv, Sills, Raviv, \& Wilansky, 2000). On the contrary, males tend to rely on themselves to solve their problems, often denying the presence of a psychological problem (Morgan and Robinson, 2003; Slone et al., 2013).

The literature is instead rather contradictory about the relationship between the degree of distress and the request for help. Although a number of research papers suggest that psychological distress is an important issue when investigating help-seeking, other studies highlight that this variable is not sufficient when deciding to consult a professional (Raviv et al., 2009; Sheffield et al., 2004; Wilson, Rickwood, Ciarrochi, \& Deane, 2002; Wilson, Deane, Ciarrochi, \& Rickwood, 2007). For example, some findings indicate that adolescents who are potentially at risk for suicide and depression are less likely to seek help (Garland and Zigler, 1994). Conversely, there is evidence that for other specific and extreme difficulties (i.e. sexual or physical abuse or health-related problems) adolescents with greater psychological distress are more likely to seek professional help as compared to those with less psychological distress (Grinstein-Weiss, Fishman, \& Eisikovits, 2005).

\section{The Barriers to Adolescents Seeking Help}

Relatively little research exists on adolescents' perceived barriers to help-seeking and or the willingness to seek help (Kuhl et al., 1997; Rickwood, Deane, \& Wilson, 2007; Sawyer et al., 2000). Gulliver, Griffiths, and Christensen (2010), in their systematic review, attempted to summarize the reported barriers to help-seeking in adolescents using both qualitative and quantitative data from 22 published surveys. They conclude that there is a paucity of high quality research in this area, with little importance on identifying help-seeking facilitators and few quantitative studies. Nevertheless, they found that the stigma and embarrassment connected to asking for help are prominent barrier themes.

In particular, stigma represents the concern about what others, including the help provider, might think of the adolescents seeking help. Other conspicuous barriers have been identified in the confidentiality and trust with respect to the source of help, difficulty in identifying the symptoms of mental illness (e.g. the lack of insight about the distress), lack of accessibility (e.g. time, transport, cost), preference for self-help, concern about the characteristics of the provider, knowledge about mental health services and fear of stress concerning the act of help-seeking (Clement et al., 2015; Rowe et al., 2014).

Specifically, for school counselors, as opposed to psychologists or psychiatrists in mental health settings, the prominent barriers are related to confidentiality and trust, and to concerns about the provider's characteristics. Indeed, the capacity of the school counseling service to provide help is related to its credibility and to the fact of being known by young people (Gulliver et al., 2010). In line with these claims, qualitative studies (Helms, 2003; Lindsey and Kalafat, 1998) highlight that the breach of confidentiality (not enough privacy at school), the dual role of the professional (who is both helper and enforcer of the school rules at the same time), tendency to favoritism, being out of touch with adolescents (he/she doesn't know much about adolescent problems) and being too busy (too many children to deal with), are concerns for many adolescents at school.

Despite these critical points, school-based interventions overcome some of the barriers related to service affordability (Husky et al., 2009). Some findings revealed that 
youths at risk for mental health problems are more likely to successfully access treatment when referred for schoolbased services, compared to community-based treatment (Colognori et al., 2012). For this reason, school-based services have been increasingly recognized as a good choice to reach the unsatisfied mental health needs of youths with anxiety disorders (Herzig-Anderson, Colognori, Fox, Stewart, \& Warner, 2012; Masia-Warner et al., 2005; MasiaWarner, Nangle, \& Hansen, 2006; Masia-Warner, Fisher, Shrout, Rathor, \& Klein, 2007).

\section{The School-Based Counseling Service Studied and the Research Aims}

The current investigation took place within a larger evaluation study aimed at assessing the effectiveness of a multicomponent school-based prevention program (named Point of View, hereinafter abbreviated as PV) implemented in northern Italy. PV has been active for more than 10 years and has progressively built its own identity, entering a growing number of schools and directly reaching over 5500 students. The program is realized by a public health agency in 14 middle and high schools. The PV model of intervention is innovative within the sphere of public prevention policies in Italy. Commonly, in fact, public health agencies in Italy collaborate with schools only for short initiatives focused on specific issues, such as alcohol or drug use. In contrast to these approaches, the distinctive element of PV consists in the continuous presence of a psychologist (or a social educator with specific training) 1 day a week in each school. The systemic and ecological approach adopted in PV foresees that this professional figure (always the same one along the academic years) should operate at various levels and with different targets (i.e. students, teachers, parents), with the general aim of empowering the entire school system to act as an effective context of prevention and early intervention for at risk behaviors in adolescence.

During the school year, the activities of the counselor range from individual counseling for students, teachers and parents, to classroom-based interventions, participation in class councils for difficult situations, and to open debates and lessons about issues concerning youths or adults. Some activities are predetermined (e.g. reception projects in all first-year classes, a number of hours dedicated to individual counseling), while others are defined according to the following PV guidelines: a continuous analysis of the needs and the priorities of interventions that involve the school principal and some referent teachers for each school; a discussion about the specific aims of each intervention with the stakeholders who asked for it; the documentation and assessment of each initiative and, finally, the discussion of the results with the involved stakeholders. Other key ingredients of PV derive from its belonging to a public health agency and include: the presence of a coordinator who periodically supervises the hardest situations and consolidates the project's guidelines; the use of meetings among all the counselors to exchange experiences and techniques; the intention to integrate prevention in the school culture and keep the interventions updated as to the changing risk behaviors of adolescents, a strong effort made towards the program's accountability and evaluation.

This paper aims to investigate one specific service offered by PV, namely the individual counseling service meant to provide early intervention for adolescents at risk of disease or mental health problems. As per the aforementioned literature, the fact that a school service provides psychological counseling for adolescents in difficulty does not guarantee that the users are actually those at high risk for mental health problems, since many authors evidenced that adolescents with some internalizing (i.e. depression) or externalizing (i.e. substance abuse) problems are less likely to seek help. In addition, one limit of previous studies is that they measured the willingness or intention of teens to seek help, and not the observed behavior (e.g. Sheffield et al., 2004; Raviv et al., 2000). Finally, to the best of our knowledge, no quantitative studies have hitherto assessed how some professional strategies targeted at teens are perceived and confirmed by the students themselves.

Our study aims to bridge these gaps in the literature, with two objectives to be pursued: (1) to obtain feedback from all students about the strategies that the counselors professionals adopt in order to reduce barriers to individual counseling; (2) to assess the service's effectiveness in reaching the teens most in need by comparing the students who have actually attended the individual counseling service (i.e. help-seekers' group) with others who did not (i.e. non-help seekers' group) on their perception of PV strategies to reduce barriers and on their risk profile (demographic characteristics, risk behaviors, and school and personal wellbeing).

The combined consideration of the two results will allow for a more well-informed discussion about the effectiveness of this counseling service as part of a multifaceted schoolbased prevention program.

\section{Method}

\section{Participants and Procedures}

This study involved 2235 secondary school students (784 males and 1446 females). The average participant age was 16.28 years $(\mathrm{SD}=1.66$, range $14-21)$ and $12.1 \%$ of them $(\mathrm{N}=270)$ were of foreign origin. They were enrolled in 11 secondary schools located in the province of Ferrara, 
a quite wealthy town in the north of Italy. Overall, 601 $(26.9 \%)$ of the students attended a classical or scientific oriented high school, while the remaining 1634 (73.1\%) were attending vocational or technical schools. They were almost equally divided into students attending the first 2 years (aged 14-16, $\mathrm{N}=1232,56.2 \%$ ) and the last 3 years (aged $17-21, \mathrm{~N}=962,43.8 \%$ ) of those schools.

The instrument was administered at the end of the school year in all the classes whose teachers accepted to concede one of their class hours to let the students fill out the questionnaire. For the questionnaires distributed in the classrooms the researcher explained the procedure and guaranteed confidentiality and anonymity. All the other classes received a note illustrating the research aims and procedures and students were invited to fill out an online version of the questionnaire. The questionnaire took approximately 20-25 min to complete. The participation rate per school ranged from 10.9 to $76.4 \%$ of the total students present in the institutes, with an average participation of $37.34 \%$.

Participation was preceded by an informed-consent procedure that required the active consent of both students and their parents. The Ethics Commission of the institution where the authors work approved this survey, which was conducted in compliance with the ethical norms defined by the Italian National Psychological Association.

\section{Instruments}

All the students were asked to indicate their gender, school, nationality, average school marks, any access to the counseling services and to fill out a questionnaire comprising the following areas:

\section{Feedback on PV Strategies to Reduce Barriers}

Twelve ad hoc items were built on the grounds of a previous study (Palareti, Mameli, \& Biolcati, 2014) that identified the specific strategies (expressed in the form of 86 short sentences) that PV experts use in order to reach their goals in each school. In particular, we selected and adapted the sentences that referred to promoting the students' use of professional counseling when needed, and assessed the enactment of each strategy on a 5-point Likert scale (from $1=$ totally untrue to $5=$ totally true). On the basis of previous discussions with $\mathrm{PV}$ professionals, such strategies addressed the following barriers: (a) to facilitate students' confidence and trust in the counselor; (b) to implement knowledge of the service and its accessibility; (c) to reduce any embarrassment linked to contacting the counselor. Since single items were used separately in the analysis, no Cronbach alpha was foreseen.

\section{Risk Behaviors—RTSHIA}

The propensity to take risk behaviors was assessed using one of the two subscales of the Risk-Taking and Self-Harm Inventory for Adolescents (RTSHIA; Vrouva, Fonagy, Fearon, \& Roussow, 2010) in its Italian validated version (Marchetti, Bracaglia, Cavalli, \& Valle, 2013), namely Risk-Taking. This scale, which was used in several studies showing good psychometric properties (e.g. Cousins et al., 2016), evaluates the frequency of unsafe behaviors with 9 items such as "Have you ever stayed out late at night, without your parents knowing where you were?". Since in Italy there is a legal distinction between so-called light and hard drugs, we chose to split the item "Have you ever used drugs (such as marijuana, cocaine, LSD, etc.)?" into two items, respectively "Have you ever taken marijuana or hashish?" and "Have you ever taken drugs (such as cocaine, LSD, etc.)?". The items were assessed on a Likert scale ranging from 1 (Never) to 4 (Many times). Cronbach alpha for this scale was 0.87 .

\section{Risk Behaviors-PV Scale}

On the basis of a specific request from PV professionals, we added six further items to the list of risk behaviors, assessed on the same Likert scale, regarding other risk situ-ations frequently encountered in their work, such as "Have you ever been victim of bullying (e.g. teasing, physical vio-lence or blackmail)?". The data was considered suitable for factor analysis following the multiple "rule of thumbs" that included the Kaiser-Meyer-Olkin (KMO) Measure of Sampling Adequacy (0.699) and Bartlett's Test of spheric-ity $\left(\chi^{2}=3423.72, \mathrm{df}=15, \mathrm{p}<.001\right)$. A principal compo-nent Factor Analysis was carried out on the six items. An inspection of the factor screen plot was conducted to determine the best number of factors to be retained. The analy-ses returned one reliable factor with acceptable eigenvalue (2.59) accounting for $43.19 \%$ of the total variance. The Cronbach alpha for this scale was 0.72 .

\section{School Wellbeing}

This scale consists in an adapted version of the School Wellbeing Inventory questionnaire, widely used in educational services in Northern Italy but not yet validated in the scientific literature. The scale is made up of 29 items (graded from $1=$ totally false to $5=$ totally true).

Kaiser-Meyer-Olkin (KMO) measure of sam-pling adequacy (0.918) and Bartlett's test of sphericity $\left(\chi^{2}=\right.$ 24499.85, df $=406, \mathrm{p}<.001)$ showed that the data were suitable for factor analysis. First, a principal compo-nent Factor Analysis without rotation was conducted on all the items. An inspection of the factor screen plot returned 
four reliable factors with acceptable eigenvalues (ranging from 8.70 to 1.27 ). After that, a principal component Factor Analysis with an oblique rotation (Oblimin criterion) confirmed the presence of four components accounting for $52.12 \%$ of the total variance. Oblimin rotation was appropriate in this study because we assumed that the factors can be correlated. More detailed data are available from the authors. The first factor or subscale, General school wellbeing $(29.99 \%$ of variance explained), consisted of 13 items and assesses the degree to which the school is perceived as a positive context, able to stimulate students' active participation and to support them in their growth (e.g. "I believe this is a good school to go to"). The second subscale, Classroom wellbeing (11.75\% of variance explained), consisted of 8 items and evaluates a positive sense of belonging to the respective classes and the level of acceptance by, and integration with, the classmates (e.g. "I feel at ease in class"). The third subscale, Negative behaviors in school (5.99\% of variance explained), consisted of four items and assesses the students' perception of hostility, bullying and exclusion episodes in the school (e.g. "Bullying is a widespread phenomenon at this school"). The fourth factor, Relationship with teachers $(4.39 \%$ of variance explained), consisted of four items that evaluate the quality of teacherstudents relationship (e.g. "I enjoy high-quality dialogue with my teachers"). The Cronbach alpha for these subscales was $0.85,0.89,0.64$ and 0.87 , respectively.

\section{Personal Wellbeing}

This area was investigated by selecting some items from the subscales of the Clinical Outcomes in Routine Evaluation-Outcome Measure (CORE-OM; Evans et al., 2000) and of the Self Esteem Questionnaire (SEQ; DuBois,
Felner, Brand, \& Phillips, 1996) in its Italian validated version (Melotti and Passini, 2002). Both questionnaires are widely used in the literature showing good psychometric properties (Emiliani, Melotti, \& Palareti, 2007; Brighi et al., 2012; Trujillo et al., 2016; Connell et al., 2007). All 12 items have a Likert scale that ranges from 1 (completely disagree) to 5 (completely agree). Four items from the CORE-OM evaluate the Psychological distress (anxious and depressive symptoms) with items such as "I often feel tense, anxious or nervous". From the SEQ we selected 5 items from the Global Self-esteem subscale (e.g. "I am satisfied with myself as a person") and 3 from the Family Self-esteem subscale (e.g. "I feel appreciated by my family"). The Cronbach alpha for these subscales was 0.82, 0.78 and 0.83 respectively.

\section{Results}

\section{Differences Between Help-Seekers and Non Help- Seekers on Socio-Demographic Characteristics}

Of the 2235 students surveyed, 333 (14.9\%) declared they had been to an individual consultation with the PV counselor. Seven students did not answer and are thus treated as missing in the analyses. There are no age differences between the two resulting groups $\left(\right.$ mean $_{\text {help-seekers }}=16.15$, mean $\left._{\text {non help-seekers }}=16.31, \mathrm{~F}=2.553, \mathrm{p}=.110\right)$. Chi square analyses (Table 1) indicates that the help-seekers include a significantly higher proportion of females (73.87 vs. $63.33 \%$ ) and of students from classical/scientific high schools (41.44 vs. $24.40 \%$ ) than non help-seekers. Also the percentage of foreigners is higher than the expected value,
Table 1 Contingency crosstabs on gender, nationality and school by help-seekers and non help-seekers groups

\begin{tabular}{|c|c|c|c|c|c|c|c|}
\hline & \multicolumn{2}{|c|}{ Help-seekers (333) } & \multicolumn{2}{|c|}{$\begin{array}{l}\text { Non help-seekers } \\
\text { (1895) }\end{array}$} & \multirow[t]{2}{*}{$\chi^{2}$} & \multirow[t]{2}{*}{$\mathrm{df}$} & \multirow[t]{2}{*}{$p$} \\
\hline & $\mathrm{N}$ & $\%$ & $\mathrm{~N}$ & $\%$ & & & \\
\hline \multicolumn{8}{|l|}{ Gender } \\
\hline Boys & 87 & 26.13 & 693 & 36.67 & 13.81 & 1 & $<0.001$ \\
\hline Girls & 246 & 73.87 & 1197 & 63.33 & & & \\
\hline \multicolumn{8}{|l|}{ Nationality } \\
\hline Italian & 276 & 83.64 & 1671 & 88.65 & 6.63 & 1 & $<0.001$ \\
\hline Foreign & 54 & 16.36 & 214 & 11.35 & & & \\
\hline \multicolumn{8}{|l|}{ School } \\
\hline Classical/scientific & 138 & 41.44 & 462 & 24.40 & 41.97 & 3 & $<0.001$ \\
\hline Technical & 106 & 31.80 & 765 & 40.40 & & & \\
\hline Vocational & 51 & 15.30 & 388 & 20.50 & & & \\
\hline Mixed* & 38 & 11.40 & 280 & 14.80 & & & \\
\hline
\end{tabular}


even though in absolute terms they are a minority (16.36 vs. $11.35 \%)$.

\section{Feedback from Students About Strategies}

Table 2 presents the feedback that all participants gave about the strategies used by PV counselors. Items are categorized according to the main barrier they address in the counselors' intentions, even if some of them may pursue a twofold purpose. Items are listed in decreasing order of mean values obtained in the whole sample; the final columns report ANOVA analysis between help-seekers and non help-seekers.

The results indicate that all the strategies aimed at fostering confidentiality and trust in the counselor obtained the highest scores; although they are not particularly high as absolute values, all the scores are above the average point of the scale. The strategies that promote service knowledge and counselor accessibility are positioned around the average point of the scale, with the exception of one item. The remaining items indicate lower concerns in the area of embarrassment and stigma.

ANOVA analysis (Table 2) shows that the help-seeking students exhibited significantly higher scores on all the items pertaining to Trust, Knowledge and Accessibility. The only two items where the two groups do not differ are in the Embarrassment and Stigma area.
We explored the differences between subgroups of students according to gender, nationality and kind of school attended. The post-hoc tests (Table 3) for the identification of significant differences between the means show that females produce higher scores in almost all the items, while males report they see the counselor more often during informal school times. The same item obtains higher scores from foreign students who, on the contrary, attribute lower scores to items related to Trust (three items) and service knowledge (two items). Finally, it appears that in vocational training schools the counselors have been more successful in obtaining spaces that foster confidentiality, while classical/scientific high school students have a better knowledge of the service and greater trust in the counselor.

\section{Differences Between Help-Seekers and Non Help- Seekers Concerning the Risk Profile}

ANOVA analysis on School achievement, School and Personal wellbeing, and Risk behaviors were carried out in order to verify whether help-seekers and non help-seekers differ as regards their risk profile (Table 4). Total scores for each of the dependent variables were used in the analysis.

Concerning students' school life, the two groups did not differ in their school marks, general school wellbeing, and in the quality of their relationships with teachers.

Table 2 ANOVA on PV strategies to reduce barriers by help-seekers and non help-seekers groups

\begin{tabular}{|c|c|c|c|c|c|c|}
\hline \multirow[t]{2}{*}{ Area } & & \multicolumn{3}{|c|}{ Means } & \multirow[t]{2}{*}{$\mathrm{F}$} & \multirow[t]{2}{*}{$p$} \\
\hline & & $\begin{array}{l}\text { All } \\
2227\end{array}$ & $\begin{array}{l}\text { Help- seekers } \\
\mathrm{N}=333\end{array}$ & $\begin{array}{l}\text { Non } \\
\text { help- } \\
\text { seekers } \\
\mathrm{N}=1895\end{array}$ & & \\
\hline $\mathrm{C} \& \mathrm{~T}$ & The counselor's way of behaving inspires closeness and trust & \multicolumn{2}{|c|}{3.263} & 3.19 & 46.670 & $<0.001$ \\
\hline C\&T & The counselor is willing to listen regardless of the adequacy of the moment or place & \multicolumn{2}{|c|}{3.213 .44} & 3.17 & 15.446 & $<0.001$ \\
\hline $\mathrm{C} \& \mathrm{~T}$ & The counselor is neutral between students and teachers & 3.21 & 3.45 & 3.16 & 16.763 & $<0.001$ \\
\hline $\mathrm{C} \& \mathrm{~T}$ & $\begin{array}{l}\text { The counselor is helpful in facilitating communication between teachers and students } \\
\text { and/or between teachers and parents }\end{array}$ & 3.15 & 3.36 & 3.12 & 11.469 & $<0.001$ \\
\hline K\&A & If I want to contact the counselor, I know how to do & 2.98 & 3.56 & 2.89 & 70.032 & $<0.001$ \\
\hline K\&A & I was informed of the various services that the counselor offers at my school & 2.92 & 3.21 & 2.86 & 20.339 & $<0.001$ \\
\hline K\&A & The counselor is just as much a part of this school as the teachers & 2.91 & 3.09 & 2.88 & 8.567 & 0.003 \\
\hline K\&A & My parents are aware of the services offered by the counselor & 2.61 & 3.11 & 2.52 & 47.410 & $<0.001$ \\
\hline $\mathrm{E} \& \mathrm{~S}$ & Contacting the counselor for a personal problem would be embarrassing & 2.43 & 2.23 & 2.46 & 9.282 & 0.002 \\
\hline $\mathrm{E} \& \mathrm{~S}$ & $\begin{array}{l}\text { It would be embarrassing to go to the counselor to ask for a consultation because I } \\
\text { might be seen by others }\end{array}$ & 2.41 & 2.36 & 2.42 & 0.646 & 0.421 \\
\hline $\mathrm{E} \& \mathrm{~S}$ & Consultations with the counselor take place in a part of school lacking in confidentiality & 2.26 & 2.16 & 2.27 & 3.273 & 0.071 \\
\hline K\&A & I can happen to see the counselor in informal moments of school life, suchas during brea & ${ }^{\mathrm{K}} 1.94$ & 2.18 & 1.89 & 16.992 & $<0.001$ \\
\hline
\end{tabular}

as during break time or at school parties 
Table 3 ANOVA on PV strategies to reduce barriers by school, gender and nationality with a synthesis of the Bonferroni post hoc tests

\section{If I want to contact the counselor, I know how to do it}

The consultations with the counselor take place in a part of school lacking in confidentiality

It would be embarrassing to go to the counselor to ask for a consultation because I might be seen by others

The counselor's way of behaving inspires closeness and trust

The counselor is just as much a part of this school as the other teachers

I was informed of the various services that the counselor offers at my school

My parents are aware of the services offered by the counselor

Contacting the counselor for a personal problem would be the cause of embarrassment

I can happen to see the counselor in informal moments of school life, such as during breaks or at school parties

The counselor is neutral between students and teachers

The counselor is willing to listen regardless of the appropriateness of the moment or place

The counselor is helpful in fostering communication between teachers and students

\begin{tabular}{|c|c|c|c|c|c|}
\hline \multicolumn{2}{|c|}{ Type of school } & \multicolumn{2}{|l|}{ Gender } & \multicolumn{2}{|l|}{ Nationality } \\
\hline $\mathrm{F}$ post hoc & $p$ & F post hoc & $p$ & F post hoc & $p$ \\
\hline 24.246 & 0.000 & 59.091 & 0.000 & 0.741 & 0.389 \\
\hline $\mathrm{C}>\mathrm{TVM}$ & & $\mathrm{M}>\mathrm{F}$ & & & \\
\hline 8.646 & 0.000 & 0.359 & 0.549 & 2.272 & 0.132 \\
\hline $\mathrm{V}<\mathrm{CT}$ & & & & & \\
\hline 2.252 & 0.080 & 9.533 & 0.002 & 0.033 & 0.856 \\
\hline & & $\mathrm{M}>\mathrm{F}$ & & & \\
\hline 29.312 & 0.000 & 83.866 & 0.000 & 19.206 & 0.000 \\
\hline $\mathrm{C}>\mathrm{T}>\mathrm{VM}$ & & $\mathrm{M}>\mathrm{F}$ & & $\mathrm{I}>\mathrm{F}$ & \\
\hline 3.124 & 0.025 & 25.27 & 0.000 & 0.442 & 0.506 \\
\hline & & $\mathrm{M}>\mathrm{F}$ & & & \\
\hline 14.489 & 0.000 & 17.927 & 0.000 & 6.654 & 0.010 \\
\hline $\mathrm{C}>\mathrm{TVM}$ & & $\mathrm{M}>\mathrm{F}$ & & $\mathrm{I}>\mathrm{F}$ & \\
\hline 25.678 & 0.000 & 35.974 & 0.000 & 12.699 & 0.000 \\
\hline $\mathrm{C}>\mathrm{TVM}$ & & $\mathrm{M}>\mathrm{F}$ & & $\mathrm{I}>\mathrm{F}$ & \\
\hline 1.553 & 0.199 & 3.179 & 0.075 & 0.169 & 0.681 \\
\hline 6.302 & 0.000 & 4.764 & 0.029 & 8.114 & 0.004 \\
\hline $\mathrm{C}>\mathrm{TVM}$ & & $\mathrm{M}>\mathrm{F}$ & & $\mathrm{F}>\mathrm{I}$ & \\
\hline 14.954 & 0.000 & 8.381 & 0.004 & 12.007 & 0.001 \\
\hline $\mathrm{C}>\mathrm{T}>\mathrm{VM}$ & & $\mathrm{M}>\mathrm{F}$ & & $\mathrm{I}>\mathrm{F}$ & \\
\hline 5.719 & 0.001 & 26.193 & 0.000 & 5.559 & 0.018 \\
\hline $\mathrm{C}>\mathrm{T}$ & & $\mathrm{M}>\mathrm{F}$ & & $\mathrm{I}>\mathrm{F}$ & \\
\hline 7.759 & 0.000 & 31.421 & 0.000 & 0.928 & 0.336 \\
\hline $\mathrm{CV}>\mathrm{T}$ & & $\mathrm{M}>\mathrm{F}$ & & & \\
\hline
\end{tabular}

Type of schools: $C$ classical/scientific, $T$ technical, $V$ vocational, $M$ mixed. Gender: $M$ males, $F$ females. Nationality: $I$ Italians, $F$ foreigners

Table 4 Analysis of variance (ANOVA) on academic achievement, school wellbeing, personal wellbeing and risk behaviours between helpseekers and non-help-seekers groups

\begin{tabular}{llll}
\hline Variables (sum range) & $\begin{array}{l}\text { Help-seekers } \\
\text { N=333 } \\
\text { Mean sum (SD) }\end{array}$ & $\begin{array}{l}\text { Non help-seekers } \\
\mathrm{N}=1895 \\
\text { Mean sum (SD) }\end{array}$ & \\
\hline Academic achievement & & & \\
School marks (4-10) & $6.81(0.88)$ & $6.90(0.91)$ & 3.02 \\
School wellbeing & & & \\
General school wellbeing (3-65) & $36.20(9.77)$ & $35.41(9.26)$ & 2.02 \\
Classroom wellbeing (2-40) & $24.98(8.25)$ & $26.25(7.57)$ & $7.68^{* *}$ \\
Negative behavior at school (2-20) & $9.36(3.54)$ & $8.82(3.31)$ & 0.85 \\
Relationship with teachers (2-20) & $10.68(4.29)$ & $10.90(3.91)$ & $33.86^{* * *}$ \\
Personal wellbeing & $15.34(4.71)$ & $16.85(4.28)$ & $49.36^{* * *}$ \\
Self-esteem (4-25) & $12.11(4.94)$ & $10.27(4.28)$ & $42.42^{* * *}$ \\
Psychological distress (2-20) & $10.90(3.33)$ & $12.08(3.00)$ & $24.45^{* * *}$ \\
Family relationships (2-15) & $16,66(7.88)$ & $18,58(9.41)$ & $76.21^{* * *}$ \\
Risk & $9.08(3.33)$ & $7.68(2.58)$ & \\
Risk behaviors-RTSHIA (5-40) & & & \\
Risk behaviors-PV (5-24) & & & \\
\hline
\end{tabular}

$* * p<.01, * * * p<.001$
The help-seekers rated a higher presence of negative behaviors in the school, and expressed a significantly lower score for their Classroom wellbeing. With regards their personal wellbeing and involvement in risk situations, the help-seekers express significantly lower scores in terms of Self-esteem and Family relationships. Conversely, they 
achieved significantly higher scores on Psychological distress and on risk behaviors (both from RTSHIA and from PV risk scale).

\section{Discussion}

The study explored the strategies used by a school prevention program to overcome barriers to individual counseling and it ascertained whether the service actually did reach the most vulnerable or problematic adolescents.

Our first goal was to obtain feedback from students on counselors' strategies to lessen the barriers to professional consultation. The results were encouraging, since the area that obtained the highest scores was the one relating to trust and confidentiality. Confidence, even more than the need for help per se, is a key variable in determining help-seeking behaviors because it is pivotal that a young individual perceives a potential helper as a good listener (Frydenberg, 1997; Gulliver et al., 2010). The average scores were not very high, but we must consider that the surveyed schools have an average of 800 students and that the counselor is there only 1 day a week. In our results, the items with the highest scores indicate that the counselor is perceived as close and available, neutral and able to foster communication between people. Students may have directly experienced these qualities as a result of being involved in one of the several initiatives over the years, or indirectly, by exchanging comments with peers. Therefore, the counselors' attitudes at school and their continuity over the years appear to be useful strategies to support their personal credibility. Our data suggest that students acknowledge the usefulness of the counselor in facilitating relationships, and they are not particularly concerned over a possible dual role or tendency to favoritism. As could be expected, confidence is higher for the help-seeker group, but even more so among classical/scientific high school students, females and Italians, categories that are significantly present in this group.

The strategies pertaining to the service information and accessibility to the counselor obtained good average scores, significantly higher for the help-seeker group. Here again, some differences appear in favor of girls, natives and classical/scientific high school students, with one interesting exception: males and foreign students claim that they see the counselor more often in informal school moments. This confirms the effective implementation of a strategy that, in the counselors' intentions, is used to make themselves more accessible and make contact with people who may have more difficulty when asking for help. Considering the high number of foreign students in the help-seeker group the goal appears to have been largely achieved.
Finally, the scores related to stigma and embarrassment are relatively low across the sample, with very few differences between the subgroups considered (by gender, type of school, nationality, help-seeking behavior). The result suggests that an open-minded culture concerning the helpseeking behavior is gaining ground in the investigated schools, presumably due to the presence of PV over the years.

The second goal of our study was to analyze the characteristics of those students who accessed the individual consultation in comparison with their peers. Our findings confirm the existing literature that reports a wider utilization of this kind of service by females (Courtenay, 2000; Dubow et al., 1990; Schonert-Reichl \& Muller, 1996; MöllerLeimkühler, 2002; Mahalik, Burns, \& Syzdek, 2007).

The fact that foreign students are over-represented in the help-seeking group is particularly noteworthy, since it goes in the opposite direction to other evidence in the literature claiming that racial or ethnic minority children and adolescents often fail to access mental health services (Cummings, Ponce, \& Mays, 2010). Thus, we endorse schoolbased services, and this one in particular, as good ways for overcoming racial/ethnic disparities and socioeconomic barriers (Garrison, Roy, \& Azar, 1999; Taras, 2004).

As regards the service effectiveness to reach teens with a higher risk profile, findings confirm that the individual counseling is used by teenagers actually in trouble, both in terms of psychological and relational difficulties and risk behaviors. As compared with their peers, the help-seekers reported lower self-esteem and more clinical symptoms. In addition, they felt less appreciated in their family and reported a worse relationship with peers than the other group. These results are consistent with previous studies (e.g. Harel, Elbogen-Frankowitz, Molcho, \& Haviv, 2002) which indicated that a lack of social support by family and friends drives adolescents to refer to other help providers perceived as trustworthy and professional (Kaim and Romi, 2015; Slone et al., 2013).

In addition, the help-seekers claimed to engage in risk behaviors more often than non help-seekers. Such data were not so obvious because professional help is less likely sought in case of externalizing problems, which are often denied or undervalued by the young (Vanheusden et al., 2008).

An interesting result is that no significant differences between the two groups were recorded as regards academic achievement and the relationship with teachers. This might represent a critical issue for PV, since a school-based service is supposed to be able to address and intervene in all school-related problems, and because school disengagement and conflicting relationship with teachers are important risk factors in adolescence (e.g. Rickwood et al., 2007). 
In our opinion, two characteristics of the PV model lie at the root of this result. Firstly, counselors consider a good alliance with teachers and school principals to be a key prerequisite for the proper functioning of the program itself. Being imbricated and seamlessly integrated as part of the school system (as indicated by one of the strategies surveyed) implies the drawback that precisely those students in strong conflict with the school find it hard to see the counselor as a viable source of help (Gulliver et al., 2010). Secondly, PV preferably addresses conflict situations with specific teachers by giving individual support to the latter, fostering communication between the counterparts, or by working in the group class. Hence, it might be unlikely for student to ask for an individual consultation for this reason. Nonetheless, given the importance of the issue, our findings suggest that PV staff should further investigate whether their global strategies are sufficient to unveil and prevent school drop-outs.

\section{Limitations, Implications for Social Work and Conclusions}

This study had some methodological limitations that ought to be taken into account. First, given the cross-sectional survey design and the correlational nature of the analysis the effectiveness of the PV strategies can only be inferred. In addition, the unique reliance on self-report data limits the range of the information available and measurement bias could have resulted from social desirability in self-reporting.

Secondly, although the response rate is considerable, the sample is not entirely representative of the teenagers to whom the program is aimed, and it may be somewhat influenced by the different involvement of teachers in the program.

Finally, not all the scales have been validated in the literature, since for the evaluative aims of our whole study we opted for tools that fit better with the context and the internal theory of PV. For instance, the 12 ad hoc items on PV strategies to reduce barriers were built starting from the sentences of PV staff that emerged in the preliminary study where this program's implicit and explicit theories were identified (Palareti et al., 2014). At times the derived items do not really describe the counselor's activity but their intended outcomes (e.g. to have space and procedures for consultations that allow for confidentiality are the results of a sometimes difficult negotiation with school staff), but this is in line with our theory-based approach to evaluation (Chen, 1994; Coryn, Noakes, Westine, \& Schröter, 2011), which aims to assess the implementation of PV's theory and its effectiveness to achieve the desired outcomes.

Notwithstanding these limitations, this study provides insights for practice and policy frameworks. PV is a new model of intervention in the Italian field of prevention; the staff share its theoretical framework and its related guidelines, but the counselors routinely manage their limited time according to the needs and resources identified in the situations and the people involved. The individual counseling is just one of the activities, and it takes its place alongside initiatives to improve the group's knowledge, skills or functioning for everyone involved in school life.

Making a judgment on the quality and effectiveness of $\mathrm{PV}$ is a complex task to carry out, as it requires breaking up the project and evaluating it with respect to the specific activities and objectives, while considering them within the overall rationale of the program. In this paper we focused on an individual student counseling service. The assessment of the strategies gave us general feedback on the consistency with which they are applied and allowed us to develop some considerations about their effectiveness. Generally, school based prevention programs have rarely been assessed, with help-seeking often measured instead as an attitudinal or intentionality construct. "Involving adolescents", comparing help-seekers with non-help seekers for feedback on counselors' strategies enables appropriate changes in practice to be made. In particular, this kind of assessment helps social workers to identify strategies that the adolescents themselves consider as facilitators with respect to the utilization of such services. Fortunately, these facilitators are more practically modifiable than demographic or structural factors, and as a result, they may be very helpful to consider in developing interventions to increase service utilization.

Given the large number of adolescents at risk of mental health problems that do not address the counseling service when needed, social workers should implement a balanced approach that comprehensively focuses on barriers to helpseeking and also on how those barriers potentially influence the approach of particular profile of adolescents.

In our results we found that individual counseling does not intercept students at risk of school failure; this point could be further explored in the evaluation of other components of PV, while the staff has already been encouraged to think about this aspect, and, if necessary, to devise innovative strategies and services for those teens with such problems.

In general, our findings suggest that a particular strength of individual PV counseling is that it should be embedded within a broader school prevention program. Hence, adolescents can meet the counselor in a variety of circumstances and he/she can work to reduce barriers by means of multiple ways. The integration in the school setting allows "infiltration" to parts of the community that other counselors would have little access to (Lalor, O'Dwyer, \& McCrann, 2006). 
In summary, the present study emphasizes the need to encompass a community orientation in help-services provision; there are real benefits for extending mental health support beyond referral to professional services into the community itself. A school-based counseling service is an ideal setting in which to help adolescents at risk to overcome barriers to help-seeking behavior if it is integrated within a continuative and trustworthy prevention program that uses evaluation to improve itself in the concrete context in which it operates (Wells, Barlow, \& Stewart-Brown, 2003; WHO, 2007).

Funding This study was funded by the Department of Education Studies; a little funding was provided by the Municipality of Ferrara city that provided funding for a little part of the wider evaluation project.

\section{Compliance with Ethical Standards}

Conflict of interest Biolcati and Palareti declares that he/she has no conflict of interest. Mameli has received two grants from the Department with a little contribution by the Municipality of Ferrara city.

Ethical Approval All procedures performed in studies involving human participants were in accordance with the ethical standards of the institutional and/or national research committee and with the 1964 Helsinki declaration and its later amendments or comparable ethical standards.

Informed Consent Informed consent was obtained from all individual participants included in the study.

\section{References}

Boldero, J., \& Fallon, B. (1995). Adolescent help-seeking: What do they get help for and from whom? Journal of Adolescence, 18(2), 193-209.

Brighi, A., Melotti, G., Guarini, A., Genta, M. L., Ortega, R., MoraMerchán, J., ... \& Thompson, F. (2012). Selfesteem and loneliness in relation to cyberbullying in three European countries. In Q. Li, D. Cross, \& P. K. Smith (Eds.), Cyberbullying in the global playground: Research from international perspectives (pp. 32-56). Chichester: Wiley-Blackwell.

Catron, T., Harris, V. S., \& Weiss, B. (1998). Post-treatment results after 2 years of services in the Vanderbilt School-Based Counseling project. In: Epstein, M. H., Kutash, K., Duchnowski, A. (Eds.), Outcomes for children and youth with emotional and behavioral disorders and their families: Programs and evaluation best practices (pp. 633-656). Austin, TX, US: PRO-ED, xviii.

Chen, H. T. (1994). Theory-driven evaluations: Need, difficulties, and options. Evaluation Practice, 15(1), 79-82.

Clement, S., Schauman, O., Graham, T., Maggioni, F., Evans-Lacko, S., Bezborodovs, N., \& Thornicroft, G. (2015). What is the impact of mental health-related stigma on help-seeking? A systematic review of quantitative and qualitative studies. Psychological Medicine, 45(01), 11-27.

Colognori, D., Esseling, P., Stewart, C., Reiss, P., Lu, F., Case, B., \& Warner, C. M. (2012). Self-disclosure and mental health service use in socially anxious adolescents. School Mental Health, 4(4), 219-230.

Connell, J., Barkham, M., Stiles, W. B., Twigg, E., Singleton, N., Evans, O., \& Miles, J. N. (2007). Distribution of CORE-OM scores in a general population, clinical cut-off points and comparison with the CIS-R. The British Journal of Psychiatry, 190(1), 69-74.

Corry, D. A. S., \& Leavey, G. (2017). Adolescent trust and primary care: Help-seeking for emotional and psychological difficulties. Journal of Adolescence, 54, 1-8.

Coryn, C. L. S., Noakes, L. A., Westine, C. D., \& Schröter, D. C. (2011). A systematic review of theory-driven evaluation practice from 1990 to 2009. American Journal of Evaluation, 32(2), 199-226.

Courtenay, W. H. (2000). Constructions of masculinity and their influence on men's well-being: a theory of gender and health.

Social Science \& Medicine, 50(10), 1385-1401.

Cousins, L., Whitaker, K. J., Widmer, B., Midgley, N., Byford, S., Dubicka, B., ... \& Barrett, B. (2016). Clinical characteristics associated with the prescribing of SSRI medication in adolescents with major unipolar depression. European Child \& Adolescent Psycbiatry, 25(12), 1287-1295.

Cummings, J. R., Ponce, N. A., \& Mays, V. M. (2010). Comparing racial/ethnic differences in mental health service use among high-need subpopulations across clinical and school-based settings. Journal of Adolescent Health, 46(6), 603-606.

D’Avanzo, B., Barbato, A., Erzegovesi, S., Lampertico, L., Rapisarda, F., \& Valsecchi, L. (2012). Formal and informal helpseeking for mental health problems. A survey of preferences of Italian students. Clinical Practice and Epidemiology in Mental Health: $C P$ \& EMH, 8, 47.

DuBois, D. L., Felner, R. D., Brand, S., \& Phillips, R. S. (1996). Early adolescent self-esteem: A developmental-ecological framework and assessment strategy. Journal of Research on Adolescence, 6(4), 543-579.

Dubow, E. F., Lovko, K. R. Jr., \& Kausch, D. F. (1990). Demographic differences in adolescents' health concerns and perceptions of helping agents. Journal of Clinical Child Psychol-ogy, 19(1), 44-54.

Emiliani, F., Melotti, G., \& Palareti, L. (2007). Représentations sociales de la vie quotidienne et bien-être chez des adolescents italiens. Revue internationale de psychologie sociale, 20(2), 27-55.

Evans, C., Mellor-Clark, J., Margison, F., Barkham, M., Audin, K., Connell, J., et al. (2000). CORE: Clinical outcomes in routine evaluation. Journal of Mental Health, 9(3), 247-255.

Frigerio, A., Rucci, P., Goodman, R., Ammaniti, M., Carlet, O., Cavolina, P., et al. (2009). Prevalence and correlates of mental disorders among adolescents in Italy: the PrISMA study. European Child \& Adolescent Psychiatry, 18(4), 217-226.

Frydenberg, E. (1997). Adolescent coping: Theoretical and research perspectives. London: Routledge.

Garland, A. F., \& Zigler, E. F. (1994). Psychological correlates of help-seeking attitudes among children and adolescents. Ameri-can Journal of Orthopsychiatry, 64(4), 586.

Garrison, E. G., Roy, I. S., \& Azar, V. (1999). Responding to the mental health needs of Latino children and families through school-based services. Clinical Psychological Review, 19, 199219.

Greenberg, M. (2010). School-based prevention: Current status and future challenges. Effective Education, 2, 27-52.

Grinstein-Weiss, M., Fishman, G., \& Eisikovits, Z. (2005). Gender and ethnic differences in formal and informal help-seeking among Israeli adolescents. Journal of Adolescence, 28(6), 765779 . 
Gulliver, A., Griffiths, K. M., \& Christensen, H. (2010). Perceived barriers and facilitators to mental health help-seeking in young people: A systematic review. BMC Psychiatry, 10(1), 113.

Harel, I., Elbogen-Frankowitz, S., Molcho, M., \& Haviv, G. (2002). Youth in Israel: An international view of social welfare, health, and risk behaviors. Joint-Brookdale Institute and Bar-Ilan Uni-versity (Hebrew), Second research findings, Jerusalem.

Helms, J. L. (2003). Barriers to help-seeking among 12th graders. Journal of Educational and Psychological Consultation, 14(1), 27-40.

Herzig-Anderson, K., Colognori, D., Fox, J. K., Stewart, C. E., \&

Warner, C. M. (2012). School-based anxiety treatments for children and adolescents. Child and Adolescent Psychiatric Clinics of North America, 21(3), 655-668.

Husky, M. M., McGuir, L., Flynn, L., Chroswski, C., \& Olfson, M. (2009). Correlates of help-seeking behavior among at-risk ado-

lescents. Child Psycbiatry Human Development, 40, 15-24. Jackson, C. A., Henderson, M., Frank, J. W., \& Haw, S. J. (2012).

An overview of prevention of multiple risk behaviour in adolescence and young adulthood. Journal of Public Health, 34(suppl. 1), i31-i40.

Kaim, Z., \& Romi, S. (2015). Adolescents at risk and their willingness to seek help from youth care workers. Children and Youth

Services Review, 53, 17-23.

Kuhl, J., Jarkon-Horlick, L., \& Morrissey, R. F. (1997). Measuring barriers to help-seeking behavior in adolescents. Journal of Youth and Adolescence, 26(6), 637-650.

Kushner, M. G., \& Sher, K. J. (1991). The relation of treatment fear-

fulness and psychological service utilization: An overview. Pro-fessional Psychology: Research and Practice, 22(3), 196.

Lalor, K., O'Dwyer, S., \& McCrann, D. (2006). Review of a community-based youth counselling service in Ireland. Children and Youth Services Review, 28(3), 325-345.

Leavey, G., Rothi, D., \& Paul, R. (2011). Trust, autonomy and relationships: the help-seeking preferences of young people in secondary level schools in London (UK). Journal of Adolescence, 34(4), 685-693.

Lindsey, C. R., \& Kalafat, J. (1998). Adolescents' views of preferred helper characteristics and barriers to seeking help from schoolbased adults. Journal of Educational and Psychological Consul-tation, 9(3), 171-193.

Mahalik, J. R., Burns, S. M., \& Syzdek, M. (2007). Masculinity and perceived normative health behaviors as predictors of men's health behaviors. Social Science \& Medicine, 64(11), 2201-2209.

Marchetti, A., Bracaglia, E., Cavalli, G., \& Valle, A. (2013). Comportamenti a rischio e autolesivi in adolescenza. Il questionario RTSHLA di Vrowva, Fonagy, Fearon, Roussow. Franco Angeli,

Milano.

Masia-Warner, C., Fisher, P. H., Shrout, P. E., Rathor, S., \& Klein, R. G. (2007). Treating adolescents with social anxiety disorder in school: An attention control trial. Journal of Child Psychology and Psycbiatry, 48(7), 676-686.

Masia-Warner, C., Klein, R. G., Dent, H. C., Fisher, P. H., Alvir, J., Albano, A. M., et al. (2005). School-based intervention for adolescents with social anxiety disorder: Results of a controlled study. Journal of Abnormal Child Psychology, 33(6), 707-722.

Masia-Warner, C., Nangle, D. W., \& Hansen, D. J. (2006). Bringing evidence-based child mental health services to the schools: General issues and specific populations. Education and Treatment of Children, 29, 165-172.

Melotti, G., \& Passini, S. (2002). L'applicazione ad un gruppo di adolescenti italiani del Self-esteem Questionnaire (SEQ). Bollettino di Psicologia Applicata, 238, 59-70.

Möller-Leimkühler, A. M. (2002). Barriers to help-seeking by men: a review of sociocultural and clinical literature with particular reference to depression. Journal of Affective Disorders, 71(1), 1-9. Morgan, N. T., \& Robinson, M. (2003). Students' help-seeking behav-

iors by gender, racial background, and student status. Canadian Journal of Counselling, 37(2), 151-166.

Palareti, L., Mameli, C., \& Biolcati, R. (2014). A proposal for a theory-driven evaluation applied to a school health promotion project. What theories guide the staff? Psicologia clinica dello svi-luppo, 18(3), 491-490.

Raviv, A., Raviv, A., Vago-Gefen, I., \& Fink, A. S. (2009). The personal service gap: Factors affecting adolescents' willingness to seek help. Journal of Adolescence, 32(3), 483-499.

Raviv, A., Sills, R., Raviv, A., \& Wilansky, P. (2000). Adolescents' help-seeking behaviour: The difference between self-and otherreferral. Journal of adolescence, 23(6), 721-740.

Rickwood, D. J., \& Braithwaite, V. A. (1994). Social-psychological factors affecting help-seeking for emotional problems. Social Science \& Medicine, 39(4), 563-572.

Rickwood, D. J., Deane, F. P., \& Wilson, C. J. (2007). When and how do young people seek professional help for mental health problems? The Medical Journal of Australia, $187(7$ Supplement), S35S39.

Rowe, S. L., French, R. S., Henderson, C., Ougrin, D., Slade, M., \& Moran, P. (2014). Help-seeking behaviour and adolescent selfharm: A systematic review. Australian and New Zealand Journal of Psychiatry. doi:10.1177/0004867414555718.

Saunders, S. M., Resnick, M. D., Hoberman, H. M., \& Blum, R. W. (1994). Formal help-seeking behavior of adolescents identifying themselves as having mental health problems. Journal of the American Academy of Child \& Adolescent Psychiatry, 33(5), 718728.

Sawyer, M. G., Arney, F. M., Baghurst, P. A., Clark, J. J., Graetz, B. W., Kosky, R. J., et al. (2000). The mental health of young peo-ple in Australia. Canberra: Mental Health and Special Programs Branch, Commonwealth Department of Health and Aged Care.

Schonert-Reichl, K. A., \& Muller, J. R. (1996). Correlates of helpseeking in adolescence. Journal of Youth and Adolescence, 25(6), 705-731.

Schonert-Reichl, K. A., Offer, D., \& Howard, K. I. (2013). Seeking help from informal and formal resources during adolescence: Sociodemographic and psychological correlates. Adolescent Psychiatry: Developmental and Clinical Studies, 20, 165-178.

Sears, H. A. (2004). Adolescents in rural communities seeking help: who reports problems and who sees professionals? Journal of

Child Psychology and Psychiatry, 45(2), 396-404.

Sheffield, J. K., Fiorenza, E., \& Sofronoff, K. (2004). Adolescents' Willingness to Seek Psychological Help: Promoting and Preventing Factors. Journal of Youth and Adolescence, 33(6), 495-507.

Slone, M., Meir, Y., \& Tarrasch, R. (2013). Individual differences in referral for help for severe emotional difficulties in adolescence. Children and Youth Services Review, 35(11), 1854-1861. Sourander, A.,

Helstelä, L., Ristkari, T., Ikäheimo, K., Helenius, H., \& Piha, J. (2001). Child and adolescent mental health service use in Finland. Social Psychiatry and Psychiatric Epidemiology, 36(6), 294-298.

Stefl, M. E., \& Prosperi, D. C. (1985). Barriers to mental health service utilization. Community Mental Health Journal, 21(3), 167-

178.

Sweeting, H., Young, R., West, P., \& Der, G. (2006). Peer victimization and depression in early-mid adolescence: A longitudinal study. British Journal of Educational Psychology, 76(3), $577-$ 594.

Taras, H. L. (2004). School-based mental health services. Pediatrics, 113, 1839-1845.

Trujillo, A., Feixas, G., Bados, A., García-Grau, E., Salla, M., Medina, J. C., et al. (2016). Psychometric properties of the 
spanish version of the clinical Outcomes in routine evaluationOutcome Measure. Neuropsychiatric Disease and Treatment, 12, 1457.

Vanheusden, K., Mulder, C. L., van der Ende, J., van Lenthe, F. J., Mackenbach, J. P., \& Verhulst, F. C. (2008). Young adults face major barriers to seeking help from mental health services. Patient Education and Counseling, 73(1), 97-104.

Vostanis, P., Humphrey, N., Fitzgerald, N., Deighton, J., \& Wolpert, M. (2013). How do schools promote emotional well-being among their pupils? Findings from a national scoping survey of mental health provision in English schools. Child and Adolescent Mental Health, 18, 151-157.

Vrouva, I., Fonagy, P., Fearon, P. R., \& Roussow, T. (2010). The risktaking and self-harm inventory for adolescents: Development and psychometric evaluation. Psychological Assessment, 22(4), 852.

Wells, J., Barlow, J., \& Stewart-Brown, S. (2003). A systematic review of universal approaches to mental health promotion in schools. Health Education, 103(4), 197-220.

WHO (2007). Adolescents, social support and help-seeking behaviour: an international literature review and program consultation with recommendations for action/Gary Barker. Department of Child and Adolescent Health and Development.

Wilson, C. J., Deane, F. P., Ciarrochi, J., \& Rickwood, D. (2007). Measuring help-seeking intentions: Properties of the general help seeking questionnaire. Canadian Journal of Counselling and Psychotherapy/Revue canadienne de counseling et de psy-chothérapie, 39(1), 15.

Wilson, C. J., Rickwood, D., Ciarrochi, J. V., \& Deane, F. P. (2002). Adolescent barriers to seeking professional psychololgical help for personal-emotional and suicidal problems. In:Suicide Preven-tion Australia 9th Annual Conference, June 2002 (pp. 1-8).

Wilson, S. J., \& Lipsey, M. W. (2007). School-based interventions for aggressive and disruptive behavior: Update of a meta-analysis.

American Journal of Preventive Medicine, 33(2), S130-S143.

Wu, P., Hoven, C. W., Cohen, P., Liu, X., Moore, R. E., Tiet, Q., \& Bird, H. R. (2001). Factors associated with use of mental health services for depression by children and adolescents. Psychiatric Services, 52(2), 189-195. 